\title{
O outro pé da sereia: A circunstância é maior que a situação
}

FERnANDa CAVACAS

Professora e ensaista

RESUMO : O NOSSO OBJECTIVO É CONSTRUIR UMA LEITURA DO SEXTO ROMANCE DE MIA COUTO, O OUTRO PÉ DA SEREIA, DECIFRANDO UM APÓS OUTRO OS DIFERENTES NIIVEIS DO TEXTO. PARTIMOS DAS ESTRUTURAS MAIS SIMPLES PARA CHEGAR ÀS MAIS COMPLEXAS, ACTUALIZANDO ESTRUTURAS DISCURSIVAS, NARRATIVAS, ACTANCIAIS E IDEOLÓGICAS. E O CONVITE PARA A LEITURA FAZ-SE DESDE LOGO PELO TÍTULO, IDENTIFICADOR TEMÁTICO, ONDE A FUNÇÃO METAFÓRICA ESPREITA ENCAMINHANDO-NOS PARA UM MUNDO MÁGICO DE UM SER MITOLÓGICO QUE É APREENDIDO A PARTIR DA ESTÁTUA DE NOSSA SENHORA, BENZIDA PELO PAPA E SÍMBOLO MAIOR DA PEREGRINAÇÃO DOS PORTUGUESES, COM A DESFAÇATEZ/ SENSATEZ DE QUEM LHE APLICA A SUA CRENÇA DESCOBRINDO-LHE DIFERENÇAS PARA SE ADEQUAR À SANTIDADE DA KIANDA, A DEUSA DAS ÁGUAS.

ABSTRACT : OUR AIM IS TO BUILD A READING OF THE SIXTH NOVEL BY MIA COUTO, O OUTRO PÉ DA SEREIA, DECODING ONE AFTER ANOTHER THE DIFFERENT LEVELS OF TEXT. WE STARTED FROM SIMPLER STRUCTURES TO REACH MORE COMPLEX ONES, UPDATING DISCURSIVE, NARRATIVE, ACTANTIAL AND IDEOLOGICAL STRUCTURES. THE INVITATION TO READING IS DONE IMMEDIATELY BY THE TITLE, THEME IDENTIFIER, WHERE THE LURKING METAPHORICAL FUNCTION IS FORWARDING US TO A MAGICAL WORLD OF A MYTHOLOGICAL CREATURE THAT IS PERCEIVED FROM THE STATUE OF OUR LADY, BLESSED BY THE POPE AND GREATEST SYMBOL OF THE PORTUGUESE PILGRIMAGE, WITH THE AUDACITY / WISDOM OF WHOM APPLIES HIS BELIEF DISCOVERING HER DIFFERENCES IN ORDER TO ADAPT THE SANCTITY OF KIANDA, THE GODDESS OF WATER.

PALAVRAS-CHAVE : IRONIA, TÍTULO, NARRADOR, PERSONAGENS, TEMPO E ESPAÇO. KEYWORDS : IRONY, TITLE, NARRATOR, CHARACTERS, TIME AND SPACE. 
onnez-nous, pour commencer, une histoire où l'on trouve peu de personnages et peu d'événements, bien conçue et bien pensée, vraie, naturelle sans être vulgaire; autant d'action qu'il est indispensable, autant de sentiment qu'il est nécessaire; qui ne languisse pas, qui ne se meuve pas trop lentement, toujours dans le même cercle, et qui, d'un autre côté, ne précipite point sa marche [...]. Que votre histoire nous amuse d'un bout à l'autre, que la conclusion nous satisfaisse et nous laisse un secret désir d'y rêver encore.

Condena-me por me ter convertido aos deuses dos brancos? Saiba, porém, que nós, cafres, nunca nos convertemos. Uns dizem que nos dividimos entre religiões. Não nos dividimos: repartimo-nos. A alma é um vento. Pode cobrir mar e terra. Mas não é da terra nem do mar. $A$ alma é um vento. E nós somos um agitar de folha, nos bracos da ventania. ${ }^{2}$

Ler Mia Couto continua a ser para um grande número de leitores esta comunhão de sentir e imaginar, de viver e de prolongar no tempo (con)vivências através da magia da palavra e de situações partilhadas com personagens distantes, mas paredes meias com as nossas dúvidas e os nossos pensamentos. E o encantamento dessa leitura prolonga-se e projecta-se na compreensão do mundo transcultural e na aceitação da pertença multicultural a um universo de que a ironia nos desvenda cíclicos episódios de fanatismo e de afirmações bacocas de supremacias de raças, crenças e civilizações.

O outro pé da sereia é o sexto romance de Mia Couto, publicado em Abril de 2007, e o primeiro que assenta explicitamente no cruzamento das viagens moçambicana e portuguesa.

Trata-se de um cruzamento de estórias situadas no Oceano Índico (entre Goa e a costa oriental de África) e especificamente em Moçambique, que se desenrolam em treze momentos narrativos encadeados em tempos muito distantes: Dezembro de 2002, actualidade da sociedade moçambicana, e (des) encontros histórico-culturais à época dos Descobrimentos Portugueses, entre 1560 e 1561. Neste caso, os factos históricos em que se baseia a narrativa coutista prendem-se com a primeira incursão católica na corte do Império do Monomotapa levada a cabo por D. Gonçalo da Silveira, o provincial dos jesuítas na Índia Portuguesa.

1. GOETHE, Johann Wolfgang, Entretiens d'émigrés allemands (AUBRIT, Jean-Pierre. 1997. Le conte et la nouvelle, Armand Colin/Masson, Paris, p.72).

2. Primeira carta do escravo Nimi Nsundi a Dia Kumari (p. 131). 
O convite para a leitura do livro faz-se desde logo pelo título: O Outro Pé da Sereia é um identificador temático, onde a função metafórica espreita encaminhando-nos para um mundo mágico de um ser mitológico que é apreendido a partir da estátua de Nossa Senhora, benzida pelo Papa e símbolo maior da peregrinação dos Portugueses, com a desfaçatez/sensatez de quem lhe aplica a sua crença descobrindo-lhe diferenças para se adequar à santidade da Kianda, a deusa das águas. De facto, não há a surpresa atónita da metade do corpo da bela mulher com cauda de peixe. Há antes a necessidade de compreensão do destino a dar aos pés da santa para que a ordem possa ser reposta.

Como diz Nimi Nsundi na sua carta de despedida a Dia Kumari:

É ela [a Kianda] que está dentro da escultura da Virgem. [...] Quando a olhei de frente confirmei que era ela, a Kianda: os cabelos, a pele clara, a túnica azul. O que sucedeu é que a nossa deusa ficou prisioneira na estátua de madeira dos portugueses. Libertar a sereia divina: essa passou a ser a minha constante obsessão. [...] o que fiz foi apenas libertar a deusa, afeiçoar o corpo dela à sua forma original. O meu pecado, aquele que me fará morrer, foi retirar o pé que desfigurava a Kianda. Só tive tempo de corrigir uma dessas anormais extremidades. Só peço que alguém mais, com a mesma coragem que me animou, decida decapitar o outro pé da sereia. (p. 142)

Assim, independentemente da função descritiva, O outro pé da sereia possui um valor conotativo que remete para outras significações anexas. Por exemplo, relembra o estilo coutista na personificação e num certo carácter desconcertante do referente, ao mesmo tempo que marca a presença do próprio autor, na sua dupla pertença cultural. Em várias entrevistas, Mia Couto diz de si próprio que se situa na confluência de culturas diferentes e aqui do que se trata é de deixar entrever o sincretismo religioso em torno do símbolo maior da primeira peregrinação católica portuguesa na corte do Império do Monomotapa, a estátua da Virgem Santíssima.

[O padre Manuel Antunes] aprendera a lançar os búzios e ler os desígnios dos antepassados. No terreiro, frente à casa, o português misturava rituais pagãos e cristãos. E procedia como nunca nenhum adivinho antes fizera: em cima de uma esteira colocava a pedra de ara que havia pertencido a Silveira. A seu lado 
se conservava um pedaço de madeira que, à primeira vista, surgia informe mas, depois, se configurava como um pé. Aquele era o tão falado membro que Nimi Nsundi havia decepado à Virgem Santíssima? Era o que constava no império: que o branco mantinha essa madeira porque ela estava benzida por Deus. Ou talvez fosse, simplesmente, o toco de pau que o carpinteiro Mendonça preparara como remendo para a estátua original. (p. 362)

Também as duas citações com que Mia Couto inicia o romance tomam a forma de epígrafes, e cumprem o papel de elementos prefaciais que nos suscitam e orientam a leitura, explicando e enquadrando o horizonte de expectativas num quadro de permanência para além da morte e de entendimento da vida que vai fluindo como a água e em que o sonho exerce o seu papel equilibrador.

A primeira epígrafe ${ }^{3}$ é o entendimento da permanência dos mortos na vida dos que partilham com eles o fluir dos dias: crença profunda na mediação dos mortos entre o sagrado e o quotidiano humano. E a segunda epígrafe ${ }^{4}$ vem apelar ao sonho como catalisador de experiências que outra coisa não são senão episódios irreais de uma vida verdadeira que será vivida algures: talvez como afirmação de fé cristã se pretenda situar essa vida verdadeira no céu e a vivência real na terra perca o seu valor sendo resgatada pelo sonho.

Em O outro pé da sereia, a organização macroestrutural do texto narrativo obedece a um plano de dezanove capítulos, treze situados no século XXI e seis no século XVI, que vão contribuindo para a construção e a desocultação da história. ${ }^{5}$ Podemos afirmar que se trata de narrações intercaladas (numa

3. Os que morreram / não se retiraram. / Eles viajam / na água que vai fluindo. / Eles são a água que dorme. / Os mortos / não morreram. / Eles escutam / os vivos e as coisas. / Eles escutam as vozes da água. (Birago Diop).

4. Desde que em alguma outra parte é que vivemos / e aqui é só uma nossa experiência de sonho... João Guimarães Rosa, Ave, Palavra)

5. Século XXI: Capítulo um - A estrela enterrada (p. 13-34); Capítulo dois - Pegadas no rio, sombras no tempo (p. 35-55); Capítulo quatro - A travessia do tempo (p. 73-92); Capítulo cinco - Viagens, infinitos retornos (p. 93-120); Capítulo sete - Os temperos da mentira (p. 135-155); Capítulo oito - Os afro-americanos (p. $157-$ 176); Capítulo dez - Uma mulher a céu aberto (p. 191-208); Capítulo onze - Um fio de cabelo atrapalhando a poesia (p. 209-225); Capítulo treze - Cartas, luvas e suspiros (p. 245-267); Capítulo catorze - Devaneios, farsas e visitações (p.269-284); Capítulo dezasseis - Uma mbira triste no porão da terra (p. 307-327); Capítulo dezassete - $O$ desaparecimento do americano (p. 329-346); Capítulo dezanove - As revelações (p. 363-382). Século XV T: Capítulo três - Primeiro manuscrito: o mar nu, escrito (p. 57-72); Capítulo seis - Baptismos e amputações (p. 121-134); Capítulo nove - Sobras, sombras, assombrações (p. 177-190); Capítulo doze - A dança do peixe-voador (p. 227-243); Capítulo quinze - Madeira sangrando (p.285-306); Capítulo dezoito - A casa da eternidade (p.347-362). 
base de duas-uma) de cuja concatenação se depreende a narrativa na sua totalidade orgânica. Numa articulação cuidadosa entre conteúdo e forma, a edição portuguesa imprimiu as páginas referentes ao texto que diz respeito ao século XVI em papel amarelado, o que empresta antiguidade à escrita e ajuda o leitor neste exercício necessário de recuo a um tempo que se reflecte na narrativa global, à semelhança de quem consulta papéis velhos para melhor compreender a actualidade.

O narrador extradiegético, para além do seu papel de contar a história em dois planos temporais, coloca-se por vezes no nível intradiegético e explicita julgamentos que lhe inspiram personagens ou acontecimentos (função testemunhal) e emite julgamentos gerais sobre o mundo, a sociedade e os homens (função ideológica), como, por exemplo, quando afirma:

A viagem não começa quando se percorrem distâncias, mas quando se atravessam as nossas fronteiras interiores. A viagem acontece quando acordamos fora do corpo, longe do último lugar onde podemos ter casa. (p. 77) Ou: A viagem termina quando encerramos as nossas fronteiras interiores. Regressamos a nós, não a um lugar. (p. 379)

Quanto ao primeiro modo da representação narrativa, a distância, o narrador está próximo de todos os factos narrados, quer os que se situam no país actual, quer os que se reportam ao século XVI, propondo em qualquer dos casos dados precisos e pormenorizados, dando a impressão de grande fidelidade e objectividade: os acontecimentos são visualizados através de descrições precisas.

Um exemplo para o primeiro caso: Ao chegar à praça, Mwadia se espantou: o que restava da barbearia não era mais que uma parede arruinada, localizada ao fundo, nas traseiras do que já havia sido um edifício. Não havia mais nenhuma outra parede. Nem tecto existia. Tudo se tinha desmoronado durante a guerra. O espaço era aberto, devassado. Mesmo assim, o velho barbeiro continuava fechando à chave, com rigor religioso, a única porta da única parede. (p. 141)

Outro exemplo para o segundo caso: Como tudo isso não bastasse, o mestre ordenou que se deitasse ao mar o elefante enjaulado. Os grumetes, de imediato, empurraram a jaula e a custo de muitos braços a fizeram transpor a amurada. 
A gaiola de ferro tombou com estrondo sobre as vagas, mas não se afundou logo como seria de esperar. Ficou vogando entre as altas ondas. Em vez de se alarmar, o elefante parecia rejubilar em se ver mergulhado nas águas. (p. 185)

As palavras "pronunciadas" pelas personagens matizam a escrita, quer em discurso directo ("- Me diga, você, minha filha, vai continuar nesse lugar que não existe?" p.106), quer em discurso indirecto livre ("Mwadia revelou: ao menos, algo iria acontecer em Vila Longe". p.106), abolindo as distâncias e tornando praticamente inexistente a barreira entre oral e escrito.

Os pensamentos e os elementos da vida psíquica das personagens materializam-se ou através da omnisciência do narrador que marca a sua consonância com eles ("Melhor assim, adivinhava-se o pensamento dos compadres. Como ali se dizia: o homem engana-se, a mulher engana. Por isso, era melhor que Mwadia se deixasse quieta, remota, calada". p.154), ou pelo uso abundante do estilo indirecto livre ("Nos dias seguintes, a visitante ainda duvidava: a idade já lhe começava a descair, que homem ainda lhe destinava cumprimentos? Mas a impressão primeira venceu e deu-lhe leveza ao adormecer: há muito que ela não sonhava em português". p.250), na construção de monólogos narrativisados que preenchem a tessitura da estória.

Quanto ao estudo narratológico do tempo, os momentos de O outro pé da sereia inscrevem-se genericamente em narrações ulteriores: trata-se de evocação de factos e por isso se utiliza o pretérito perfeito ou imperfeito, interrompido por comentários retrospectivos no presente. Essa evocação realizase em dois momentos temporais diferentes, marcados cronologicamente e fazendo ambos parte do passado.

O tempo de uma das estórias cumpre-se em trinta e um dias, durante o mês de Dezembro de 2002, e é marcado pela partida e pelo regresso de Mwadia Malunga a Antigamente. Já a viagem de D. Gonçalo da Silveira entre Goa e Moçambique inicia-se em Janeiro de 1560 e acaba em Março de 1561, embora se projecte ainda pelos cinco séculos que medeiam as duas estórias.

Também ao longo da narrativa, o modo singulativo é o privilegiado: o narrador conta uma vez o que se passou uma vez, ou várias vezes o que se passou várias vezes. Assim a dinâmica narrativa desenvolve-se sem quebra de interesse do leitor, não havendo lugar nem ao modo repetitivo (contar várias vezes o que apenas se passou uma vez), nem ao modo iterativo (contar uma vez o que se passou várias vezes). 
Finalmente, a ordem entre o encadeamento lógico dos acontecimentos e a ordem segundo eles são contados é linear no que diz respeito ao desenvolvimento das viagens (em cada uma das estórias) e ao progressivo entrelaçamento do(s) sagrado(s) e é discordante já que as anacronias narrativas tomam a forma de analepses e podem ser objectivas (se resultam do narrador omnisciente responsável pelo conjunto da narrativa) ou subjectivas (se testemunham uma certa flutuação da memória da personagem narradora). Um exemplo de analepse é a recordação da altura em que veio a menopausa a Dona Constança: "E explicou-se: quando lhe surgiu a menopausa ela passou a ser visitada sempre pelo mesmo sonho. E sonhava que tinha convocado familiares e amigos para uma festa de arromba". (p. 199)

Quanto ao espaço, ao longo da narrativa, as pausas descritivas, longe de denunciarem um carácter artificial da ficção, correspondem habilmente à necessidade interna da história de se situar num território humano e paisagístico adequado ao seu desenvolvimento. De um modo geral, os assuntos são descritos por ancoragem (na sequência da identificação do assunto) o que facilita a compreensão do texto e é próprio do tom oralizante do discurso, embora nalguns outros casos a afectação imprima um certo tom misterioso à descrição: "Chegada à outra margem, a mulher encheu o peito medindo forças com o horizonte. As árvores que ela vislumbrara frondosas junto ao rio eram aqui uma ossatura vegetal, ramos indigentes raspando os céus. Árvores de rapina”. (p. 78)

Um dos processos mais eficazes de tornar natural a descrição é o que Mia Couto utiliza ao introduzi-la através de um narrador que, em vez de interromper a narrativa, relata o que vê, diz ou pensa ele próprio ou outra personagem. Assim, por exemplo, acompanhamos o aparecimento da estátua de Nossa Senhora, do baú de madeira meio apodrecido e do esqueleto (de D. Gonçalo da Silveira) no chão da floresta, através de Madzero e da mulher, personagens qualificadas para ver/descrever.

Mwadia procurava as roupas que o rio arrastara quando soltou um grito. O pastor acorreu, esbaforido. Seus olhos se petrificaram. Entre os verdes sombrios, figurava a estátua de uma mulher branca. Era uma Nossa Senhora, mãos postas em centenária prece. As cores sobre a madeira tinham-se lavado, a madeira surgia, aqui e ali, espontânea e nua. O mais estranho, porém, é que a Santa tinha apenas um pé. O outro havia sido decepado. (p. 46) 
Com a utilização do modelo semiótico da narrativa, mais do que estudar o texto, visamos esclarecer a noção de sentido, i.e, graças à focagem na gramática narrativa é possível analisar o efeito-valor da estória, a maneira como ela veicula uma ideologia e a transmite ao leitor. Os percursos narrativos das personagens - que se orientam para um objecto determinado: enterrar um passado para poder caminhar no sentido do futuro - revelam os valores que as animam, os meios utilizados para o obter e as determinações que estão na origem da(s) viagem(ns). Assim, poderemos compreender a lógica que sustenta o comportamento dos actantes.

Deter-nos-emos especialmente na que consideramos ser a personagem principal - Mwadia Malunga, a mulher do burriqueiro, elo condutor das várias estórias em presença, cujo programa narrativo recupera e interpreta os diversos papéis das outras personagens e estabelece um paralelismo com a viagem da Santa e a necessidade premente de lhe encontrar um lugar (uma igreja) para que ela possa, finalmente, descansar: "Junto ao tronco [de um largo embondeiro], ela depositou a Virgem, se ajoelhou e disse: - Você já foi Santa. Agora é sereia. Agora é nzuzu”. (p.380)

O ser da personagem depende em primeiro lugar do nome próprio que, ao sugerir uma individualidade, é um dos instrumentos mais eficazes do efeito do real. Ora, uma das áreas de grande criatividade da escrita coutista é exactamente a do baptismo das suas personagens. Nenhum nome ${ }^{6}$ aparece por acaso e somos levados a acreditar que neste universo o nome de uma pessoa contém um pouco da sua alma, havendo de facto correspondência entre o carácter dela e aquilo que o autor lhe chama. Mia Couto aplica a máxima latina: Nomen omen ( $O$ nome é um presságio) e o baptismo das suas personagens

\footnotetext{
6. No mundo dos bantus a pessoa não nasce. Renasce. E recebe o nome de um morto antigo, porque nome é veículo de reencarnação. Nome é personalidade, destino, religião, sexo. Há nomes que são expressão de felicidade ou de amargura. Nomes de sonhos, de desilusão e desespero. De bravura. De cobardia. De grandeza. De humildade. [...] Nome é herança sagrada. É matéria, espírito, vida e morte. Através dele os mortos se encarnam e os vivos transmigram. Nome é anterioridade e posteridade. Em resumo, é o universo inteiro em poucas palavras. (Paulina CHIZIANE. 2000 - O Sétimo Juramento, Ndjira, Maputo, p.61 e 83); É comum entre nós esta coisa de dar nomes de família. São cadeias de afectos e de destinos. Muitas vezes aquele que herda o nome também lhe acontece a mesma sorte. O nome, sabe-se, traça o destino. Quando nasce a criança fica condenada a viver a sorte ditada pelo antepassado que ostentou em outra vida o seu nome. É assim entre nós. (Nélson SAÚTE. 2000 - Os Narradores da Sobrevivência. Romance, Publicações Dom Quixote, Lisboa, p. 117).
} 
prenuncia-lhes um destino. Aliás, a propósito do seu rebaptismo, o padrasto de Mwadia explicita: "Ter um só nome: é isso que apressa a morte. [...] E ela admitia, contrafeita, que o padrasto tinha a sua razão: deram-nos nome como um modo de nos dizerem que não temos eternidade". (páginas 83 e 84)

Ora, Mwadia Malunga, a que tinha corpo de rio e nome de canoa, é a esposa de Zero Madzero e é a ela que cabe o principal papel de viajante em que "ela se trocava em nome da salvação de Zero e do seu mundo solitário”. (p.77) Mwadia quer dizer canoa em si-nhungwé, de acordo com uma nota explicativa do próprio autor - o que é totalmente adequado para o procedimento da personagem. Quanto a Zero Madzero, o lunático pastor de burros, que "se aproximava do próprio nome: ele se anulava, em ocaso de si mesmo e até a sua voz se tornara episódica como se ele estivesse existindo por conta de um outro que já vivera", repete no nome o zero que representa a sua vida arredada de convivências, já que ma-é o prefixo do plural de várias línguas bantas.

De facto, cumprindo embora o papel tradicional feminino na sociedade moçambicana ("A mulher regressava à sua condição de esposa: retirou-se, convertendo-se em ausência. Lá fora, ela se dedicaria à sua mais antiga vocação: esperar". p.29), a força desta mulher que assume a missão de encontrar um destino para a estátua de Nossa Senhora em Vila Longe, a sua terra natal, fica patente aos olhos do leitor e corresponde inteiramente à metáfora da canoa que nos leva a bom porto e em segurança. Ao longo da narrativa, ela é identificada pelo nome próprio, às vezes, pelo diminutivo Mwadinha e como a esposa ou a filha. No entanto, foi a ele - zé-ninguém cujos únicos valores são os burros e os cabritos - que coube enterrar a estrela e é a vida dele que corre perigo já que a maldição do missionário o ferira, incumbindo-o de levar a Santa para lugar sagrado; ou, noutra perspectiva, a quem o escravo Nimi Nsundi passa o testemunho de completar a transformação por si iniciada ao cortar à santa um dos pés: "Só peço que alguém mais, com a mesma coragem que me animou, decida decapitar o outro pé da sereia.” (p. 242)

Não deixa de ser curioso que esta missão que cruza cinco séculos seja confiada a uma mulher por entreposta pessoa, ainda por cima um homem dado como morto na terra natal de ambos. Será que a tradição pesou nesta escolha ou o autor quis, também aqui, estabelecer um paralelo entre D. Gonçalo da Silveira e a estátua de Nossa Senhora e Madzero e Mwadia? O certo é que a viagem da Virgem acaba pela mão de uma mulher: "A viagem termina quan- 
do encerramos as nossas fronteiras interiores. Regressamos a nós, não a um lugar." (p.379)

Entretanto, embora os papéis temáticos possam ser muito numerosos, só são pertinentes para a compreensão de $O$ outro pé da sereia os que participam dos eixos preferenciais e que reenviam para o tema geral: o simbolismo da estátua de Nossa Senhora coxa. E nesse sentido referimos apenas mais duas personagens que se posicionam sempre em relação a este símbolo, embora obviamente de formas muito diversas - diremos, até complementares em alguns casos.

O padre Manuel Antunes, jovem sacerdote que se estreava nas andanças marítimas na viagem de Gonçalo da Silveira de Goa a Moçambique, em Janeiro de 1560, e de cujos braços a estátua de Nossa Senhora, benzida pelo Papa, escorregou no carregamento da nau Nossa Senhora da Ajuda; e Nimi Nsundi, o escravo negro que se lança nas águas turvas e salva a Virgem Santíssima. Além de mainato em terra, Nimi Nsundi é estrinqueiro há cinco anos no mar e, nesta viagem, assume novas funções: auxiliar de meirinho, a quem compete acender lume e dar luz ao próprio missionário. Trata-se de um homem originário do Reino do Congo que fora trocado por uma espingarda, cem espoletas, cinquenta balas de chumbo, um barril de pólvora e uma pipa de cachaça. Com espírito rebelde e uma incontida altivez, veste-se com aprumo e fala português, assumindo perante Dia Kumari, a aia indiana de Dona Filipa, que a deusa que o escuta quando se ajoelha perante o altar da Virgem é a Kianda.

Os programas narrativos de Zero Madzero e Mwadia Malunga são paralelos dos do Padre Manuel Antunes e Nimi Nsundi e podemos mesmo considerar que por vezes são projecções uns dos outros. A uni-los, a incumbência que obriga Zero a encontrar um lugar digno para a estátua na terra moçambicana; a diferenciá-los, as vivências das personagens, os seus passados, as suas pertenças. Assim, os papéis de adjuvante/oponente que desempenham nos programas narrativos respectivos conferem-lhes uma ambiguidade significativa só explicável pelo conflito interpretativo da estátua, agravado pela incompreensão mútua, mas que a palavra escrita das cartas de Nsundi ajuda a compreender e antecipa o lugar encontrado por Mwadia para a Santa.

A manipulação, no caso de Nsundi, centra-se no desejo de dar a forma autêntica à estátua da Virgem; no caso do Padre, na tentativa de catequizar os ímpios e de lhes impor a religião, num primeiro momento, na aceitação 
da mudança, ao longo da viagem: "Estou transitando de raça, D. Gonçalo. E o pior é que estou gostando mais dessa travessia do que de toda a restante viagem". (p.190)

Depois, ambos vão dando provas da competência que têm/não têm para continuar a viagem, mas aqui merece especial relevo o facto de o escravo conhecer mais das crenças alheias e de ser capaz de procurar algum sincretismo na fé. O desempenho de cada um deles vai ajudando à construção de uma relação que os torna diferentes, mas os isola do mundo que não muda e se traduz na morte do escravo e no rebaptismo do sacerdote. Talvez, no entanto, ainda seja cedo para a intercompreensão e seja preciso esperar cinco séculos para Zero e Mwadia, o casal de Antigamente, poder perseguir o seu sonho (sanção) e encontrar no tronco da árvore sagrada a melhor igreja para a santa.

A avaliação e a interpretação do cumprimento da(s) missão(ões) de Antunes e Nsundi cruzam-se, assim, com a avaliação e a interpretação da(s) missão(ões) de Zero e Mwadia: "O tempo jazia agora sob o firme chão. O passado apodreceria sob os seus pés, juntando-se ao estrume da terra” (p. 382)

Finalmente e no que diz respeito à importância hierárquica dos diferentes actores do romance, somos levados a concluir que Mwadia e Nsundi são protagonistas indissociáveis, herói duplo de um mesmo percurso de sentido contrário à imposição de uma fé que não é a deles. Escolher um deles usando a qualificação, a distribuição, a autonomia e a funcionalidade, seria privilegiar apenas parte do sentido que o autor quis conferir a estas duas personagens complementares, que convencionalmente representam o passado e o presente do homem africano. De facto, se Nsundi inicia o caminho da libertação, Mwadia torna-se a sua continuadora e é ela que percorre os caminhos da interioridade para compreender plenamente o sentido do sagrado.

Há, no entanto, uma nítida valorização desta personagem feminina, cuja presença tutelar se vai fazendo sentir ao longo do romance e que, de alguma forma, incorpora também a indiana Dia Kumari, personagem secundária, que, ao ficar grávida de Nsundi, o projecta para além da morte - quem sabe, tornando-o antepassado do afro-americano Benjamim Southman. A brasileira Rosie e o historiador Benjamim, o casal americano que vem à procura dessa história dos escravos; o barbeiro Arcanjo Mistura; o funcionário dos correios, velho pugilista Zeca Matambira; a mãe, Dona Constança Malunga; o padrasto, alfaiate Jesustino Rodrigues; a tia Luzmina Rodrigues; o duvidoso empresário Chico 
Casuarino; o curandeiro Lázaro Vivo; Singério, o ajudante de costureiro que adoptou o nome inspirado na máquina a pedais, são personagens secundárias que vão assumindo algum protagonismo quando nos dão as suas versões $\mathrm{da}(\mathrm{s})$ estória(s). Nessa altura, saem da sombra e participam mais activamente no caminho que Mwadia percorre dentro de si mesma. Também as personagens de há cinco séculos ajudam essa travessia, através da leitura dos livros e manuscritos coloniais que permitem "o entrelaçar dos tempos com as memórias, a restituição das cascas ao estilhaçado ovo - até porque um livro é uma canoa e esse era o barco que lhe faltava em Antigamente. Tivesse livros e ela faria a travessia para o outro lado do mundo, para o outro lado de si mesma". (p. 278)

Assim, o padre Manuel Antunes apresenta-se primeiramente como suporte do jogo de antecipação que constrói a leitura e o "sentido" do romance (efeitoorigina) para finalmente ganhar o valor de pretexto, elementos de uma situação que importa viver imaginariamente. Para lá do investimento afectivo que somos levados a fazer em relação às personagens, projectamos o horror da morte de D. Gonçalo da Silveira com os três assassinos suspeitos e compreendemos à luz da História os valores que o norteavam. A esse propósito, recordamos a pergunta que Manuel Antunes lhe faz: "Tem sentido irmos evangelizar um império de que não conhecemos absolutamente nada?”' (p. 186)

Em síntese, ao longo de todo o romance, o narrador não descurou nenhum pormenor, captando o seu leitor de múltiplas maneiras e compondo as personagens de forma a, por um lado, dar-lhes realidade individual que faça entrar em jogo o sistema de simpatia, por outro, diluir essa individualidade numa universalidade muito mais significativa.

Entretanto, esta breve análise não pode deixar de detectar neste romance de Mia Couto alguns aspectos recorrentes em toda a sua obra. Daremos exemplos pontuais de:

\section{- forma oralizante do discurso}

Mwadia passou a noite em claro. De que valia dormir se ela não adormecia os sonhos? (p.43) Mwadia revelou: ao menos, algo iria acontecer em Vila Longe. (p.106) Afinal, fora isso que ele dissera ao despedir-se da brasileira. Que iria pelo rio e se demoraria uns tempos. E foram exactamete essas palavras que, dois dias depois, Rosie viria a repetir perante os atónitos habitantes de Vila Longe. (p.336) 


\section{- ditos, sentenças ou provérbios como método recorrente de apresen- tação de sentimentos ou pensamentos}

A melhor maneira de fugir é ficar parado. (...) A melhor maneira de mentir é ficar calado. (p. 20)

A saudade é um morcego velho que falhou fruto e mordeu a noite. (p. 80)

... as pessoas é que abrigam a casa, a ternura é que sustenta o tecto. (p. 81)

A nossa lingua materna não é a palavra. O choro é o nosso primeiro idioma. (p. 200)

A saudade é uma tatuagem na alma: só nos livramos dela perdendo um pedaço de nós. (p.

... lançara a escada, mas não se faziia à abordagem. (p. 250)

O encantamento é uma casa que tem o silêncio por tecto. (p. 264)

A vida são fósforos, acendendo-se uns em outros que se apagam. (p. 324)

O que se perde em amnésia, ganha-se em amnistia. (p. 321)

... feridas da boca curam-se com a própria saliva. (p. 360)

- incursão no mundo mágico e mítico (que explica e implica acontecimentos e comportamentos das personagens envolvidas na trama narrativa)

Cumpridas as saudaçoes, Zero Madz̧ero retirou do bolso uma porção de farinha que espalhou junto a um tronco de embondeiro. (...) - A farinha está onde a deixei, vamos entrar na floresta! (p. 42-43)

Esta emigração para longe do corpo era uma arriscada doença: a primeira coisa que faz̧ia ao acordar era cuspir poeiras, babugens e espinhos. (...) Mas essa sujidade nocturna é que a ensinava: tudo, neste mundo, é bumano. (p. 314)

- transgressões formais (que permitem reintegrar a análise da forma no estudo sociológico e não negligenciar a dimensão estética do texto - dimensão fulcral no estudo da obra de Mia Couto)

a) Brincriação vocabular

... Jesustino parecia Jesus sem tino... (p. 263)

Ele quase a si mesmo não se enxergava. Como diria o alfaiate: ele era um cegocêntrico. (p. 340) 
- E durante a guerra, nunca saiu daqui?

- Não sou desses mudançarinos. (p. 316)

- ... a mais pequenita coisa é uma fortuna...

- Uma fortunissima, reforçou o curandeiro. (p. 318)

- .. o senhor se considera um animista?

- Do modo como está o mundo, eu me considero mais um desanimista. (p. 318)

b) Desconstrução de frases

... antes à tarde do que nunca. (p. 250)

A sua vida decorria entre o zelo e o selo. (p. 258)

Tenho a pulga atrasada na orelha... (p. 259)

... não dá ponte sem nó... (p. 260)

Não posso falar, a voz colou-se-me. (p. 261)

Em terra de cegos quem tem um olho vê melhor do que os que nada enxergam. (p. 311)

Dos fracos não pesa a História. (p. 325)

- recurso frequente à ironia (que consiste num jogo duplo, num mecanismo de refutação que desvaloriza para valorizar ou valoriza para desvalorizar. Além disso, deixa-se ao leitor, apoiado no contexto, a interpretação, num processo de dissimulação pelo qual se esquece o fanatismo rectilíneo - pois o regime natural da ironia é o "pizzicato" - e se liberta o espírito dos falsos valores, desenvolvendo o sentido da relatividade, de uma outra filosofia).

a) Ironia verbal

E o barbeiro anunciou, enfático: auscultação é uma desculpa que os médicos usam para declarar todos válidos para morrer. Avançam com o estetoscópio, encostam uma extremidade ao peito da vítima e vão ordenando ao infeliz que inspire umas trinta vezes. No final, quando o desgraçado está sem fôlego, a condenação é pronunciada sem apelo: apto para todo o serviço! (p.142)

b) Ironia dramática / situacional / de acontecimento

- Os desgraçados se envenenaram.

(...) 
Na noite anterior, alguns escravos tinham assaltado a cabina do piloto e roubado mapas. (...)

Os escravos tinham comido os mapas. Amoleceram as cartas em água e devoraram-nas. $O$ que eles não sabiam era que as tintas eram venenosas. O médico ironizou, em provocação: - Se ainda tivessem comido a Europa... Mas os tipos foram logo comer África. Esse é o continente mais venenoso. (p.182, 183)

c) Ironia das cenas

... o que restava da barbearia não era mais que uma parede arruinada, localizada ao fundo, nas traseiras do que já havia sido um edifício. Não havia mais nenhuma outra parede. Nam tecto existia. (...) Mesmo assim, o velho barbeiro continuava fechando à chave, com rigor religioso, a única porta da única parede. (p.141)

Através de todo este percurso, o nosso objectivo foi construir uma leitura do romance $O$ outro pé da sereia, decifrando um após outro os diferentes níveis do texto. Partimos das estruturas mais simples para chegar às mais complexas, actualizando estruturas discursivas, narrativas, actanciais e ideológicas. $\mathrm{O}$ valor atribuído pelo texto ao sujeito, ao objecto e aos outros papéis actanciais permite resgatar a visão do mundo veiculada pelo romance. E essa visão não depende da experiência do leitor, mas das formas e da organização do próprio texto. E, embora seja impossível determinar a experiência de cada leitor, podemos afirmar que Mia Couto nos oferece uma oportunidade de subversão na conformidade, eleição do sentido na polissemia e modelização por uma experiência de realidade ficcional: em suma, uma prática frutuosa de que sairemos obrigatoriamente transformados, ou não fosse o escritor afinal um cicerone cego de um lugar em risco de invenção, um cientista de miragens que nos permite, numa só vida, usufruir os milénios que o mundo tem. ${ }^{7}$

Recebido em 05 de abril e aprovado em 16 de maio de 2010.

7. Mia COUTO - Camões na Mafalala, in Jornal de Letras, 1991-08-13:11. 